\title{
Pregnant Women on Thyroxine Substitution Are Often Dysregulated in Early Pregnancy
}

\author{
Bengt Hallengren, ${ }^{1}$ Mikael Lantz, ${ }^{1}$ Bengt Andreasson, ${ }^{2}$ and Lars Grennert ${ }^{3}$
}

Background: Thyroid hormones are important for normal fetal development. Maternal hypothyroidism during early pregnancy is associated with impaired neuropsychological development of children and other adverse outcomes. The primary aim of this prospective study was to determine whether thyroxine-treated pregnant women with hypothyroidism are adequately thyroxine substituted in early pregnancy. A secondary aim was to determine if fetal loss differed between females with thyrotropin (TSH) values within and outside the reference range at their first TSH test, scheduled for 1-2 weeks after verification of pregnancy.

Methods: This was a prospective open-labeled study. During the years 1997-2002, 119 consecutive pregnancies in 101 females with thyroid diseases were followed at the Department of Endocrinology, Malmö University Hospital. At the first visit, 63 patients, median age 30 years (range 17-45 years), were on thyroxine substitution therapy for hypothyroidism. In these patients $83 \%$ were in their first trimester at the time of the initial test.

Results: Of the 63 patients on thyroxine substitution for hypothyroidism 32 (51\%; Group A) patients had serum TSH values within the reference range at their initial test and 31 (49\%; Group B) had serum TSH values outside the reference range. Twelve (19\%) had TSH values of $<0.40 \mathrm{mIU} / \mathrm{L}$ and $19(30 \%)$ had TSH values of $>4.0 \mathrm{mIU} / 1$. The fetal loss was 2 of $32(6 \%)$ in Group A compared to 9 of $31(29 \%)$ in Group B $(p<0.05)$.

Conclusions: In $49 \%$ of pregnant women on thyroxine substitution, serum TSH values were outside the reference range when first tested, generally in the first trimester. Fetal loss was significantly greater in pregnant women with abnormal TSH values compared to those with normal TSH values. Thyroid function in pregnant women on thyroxine substitution should be monitored early in pregnancy and carefully followed during pregnancy. The thyroxine dose should be increased as needed early in pregnancy to avoid hypothyroidism.

\section{Introduction}

T HYROID DYSFUNCTION in pregnant women can influence the outcome for mother and fetus at all stages of pregnancy as well as interfere with ovulation and fertility (1-3). Maternal hypothyroidism during early pregnancy is associated with impaired neuropsychological development of children and other adverse outcomes, including premature birth, preeclampsia, breech delivery, and increased fetal mortality (4-8). These complications are seen in overt hypothyroidism, which occurs in about $0.2 \%$ of pregnancies, as well as subclinical hypothyroidism, found in about $2.3 \%$ of pregnancies (9). Maternal overt hyperthyroidism is associated with fetal loss, fetal growth restriction, preeclampsia, and preterm delivery $(1,10)$, whereas subclinical hyperthyroidism has not been specifically associated with adverse pregnancy outcomes in a study in which $1.7 \%$ of pregnancies were associated with subclinical maternal hypothyroidism (11). As the fetus is entirely dependent on maternal thyroid hormones for its development until about 13 weeks of gestation, it is important to ensure adequate thyroxine substitution in pregnant women during the first trimester (2). The aim of this prospective study was to explore whether thyroxine-treated pregnant women with hypothyroidism are adequately thyroxine substituted in early pregnancy. A secondary aim was to determine if fetal loss differed between pregnant women with normal and abnormal plasma thyrotropin (TSH) values obtained in early pregnancy.

\section{Material and Methods}

The town of Malmö is generally considered to be iodine sufficient although iodine data from recent years are lacking. The study was approved by the Ethical Review Board of Lund University, Malmö/Lund, Sweden.

During the years 1997-2002, 119 consecutive pregnancies in 101 females with thyroid diseases were followed at the outpatient clinics, Department of Endocrinology, Malmö

${ }^{1}$ Department of Endocrinology, ${ }^{2}$ Department of Pediatrics, ${ }^{3}$ Department of Gynecology and Obstetrics, Malmö University Hospital, Malmö, Sweden. 
University Hospital. At the first visit 63 patients (median age, 30 years; range, 17-45 years) were on thyroxine substitution for hypothyroidism. The etiologies of their hypothyroidism was autoimmune thyroiditis (AIT) in 35, ablative treatment for Graves' thyrotoxicosis in 20 (postsurgical $=13$, radioactive iodine $=7$ ), and other causes in eight. Nine other patients had active hyperthyroidism. This was due to Graves' disease in seven and toxic multinodular goiter in two.

Females in Malmö are followed regularly during pregnancy at an antenatal care unit or at a specialist antenatal care center at the Department of Gynecology and Obstetrics. Patients with known or suspected thyroid diseases are referred to the Department of Endocrinology. The patients in this study were referred from the antenatal care unit, the specialist antenatal care center, or the primary care unit or were already regular patients at the Department of Endocrinology, Malmö University Hospital. In the latter group the patients had previously been instructed to contact the clinic as soon as they found out they were pregnant. They had their first visit and TSH test within 1-2 weeks after pregnancy was established. Patients were followed every 4 to 8 weeks during pregnancy at the outpatient endocrine clinic. Before each visit serum free thyroxine $\left(\mathrm{FT}_{4}\right.$; reference range, $9-22 \mathrm{pmol} / \mathrm{L}$ ) and TSH (reference range, $0.4-4.0 \mathrm{mIU} / \mathrm{L})$ concentrations were determined. In patients on thyroxine substitution, the dose was adjusted as needed, usually by $25-50 \mu \mathrm{g}$, to maintain the TSH concentration within the reference range and, during the first two trimesters, below $2 \mathrm{mIU} / \mathrm{L}$. A low TSH value was accepted in the first trimester without changing the thyroxine dose.

TSH and $\mathrm{FT}_{4}$ were measured on the Technicon Immuno $1^{\circledR}$ system (Bayer Inc., Pittsburgh, PA). Reference ranges were established in Sweden on nonpregnant subjects.

\section{Statistical analysis}

Statistical analysis of differences was determined by chisquare test. A $p$ value of $<0.05$ was considered significant.

\section{Results}

\section{Patients on thyroxine substitution for hypothyroidism}

Of the 63 patients on thyroxine substitution for hypothyroidism $32(51 \%)$ had serum TSH values within the reference range at their first TSH test and therefore were assigned to Group A. Thirty-one (49\%) had TSH tests outside the reference range and were therefore assigned to Group B. Figure 1 shows the distribution of TSH values in the 63 pregnant women on thyroxine substitution due to hypothyroidism. In 12 patients TSH was $<0.40 \mathrm{mIU} / \mathrm{L}$ and in 9 of these, TSH was $\leq 0.1 \mathrm{mIU} / \mathrm{L}$. In 19 patients TSH was $>4.0 \mathrm{mIU} / \mathrm{L}$ and in 9 of these, TSH was $>10 \mathrm{mIU} / \mathrm{L}$. Forty-two $(67 \%)$ of the patients had to increase their thyroxine dose during pregnancy. The median increase in the dose was by $50 \%$ (from 100 to $150 \mu \mathrm{g}$ ). The first blood sample was collected in first trimester in 52 of $63(83 \%)$ patients, at the gestational week 8.5 (median range $3-$ 13 weeks). In 34 of 52 patients the first dose change was performed at gestational week 11 (median range 3-32 weeks). The dose was increased on two to three occasions in 10 patients and the second and third changes made during gestational weeks 11-35. Fetal loss occurred in 2 of $32(6 \%)$ patients in Group A as compared to 9 of $31(29 \%)$ patients in Group B

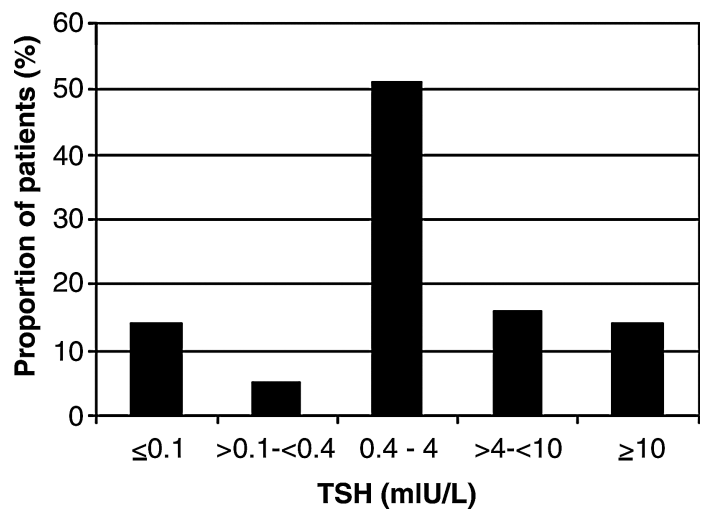

FIG. 1. Serum thyrotropin (TSH) values at first laboratory control in 63 female pregnant patients on thyroxine substitution due to hypothyroidism.

$(p<0.05)$ (Fig. 2). In Group B, four of nine patients had a TSH value $<0.4 \mathrm{mIU} / \mathrm{L}$ and five patients had a $\mathrm{TSH}$ value $>4.0 \mathrm{mIU} / \mathrm{L}$ (Table 1).

\section{Patients with hyperthyroidism}

Fetal loss occurred in three of the nine patients with active hyperthyroidism, all having Graves' disease.

\section{Discussion}

In this prospective study we found that $30 \%$ of patients on thyroxine substitution had an elevated TSH concentration when first tested during pregnancy. This is in agreement with previous studies $(6,12-15)$ and a very recent study of Vayida et al. (16) who found that nearly one quarter (22.9\%) of hypothyroid women on thyroxine replacement had elevated

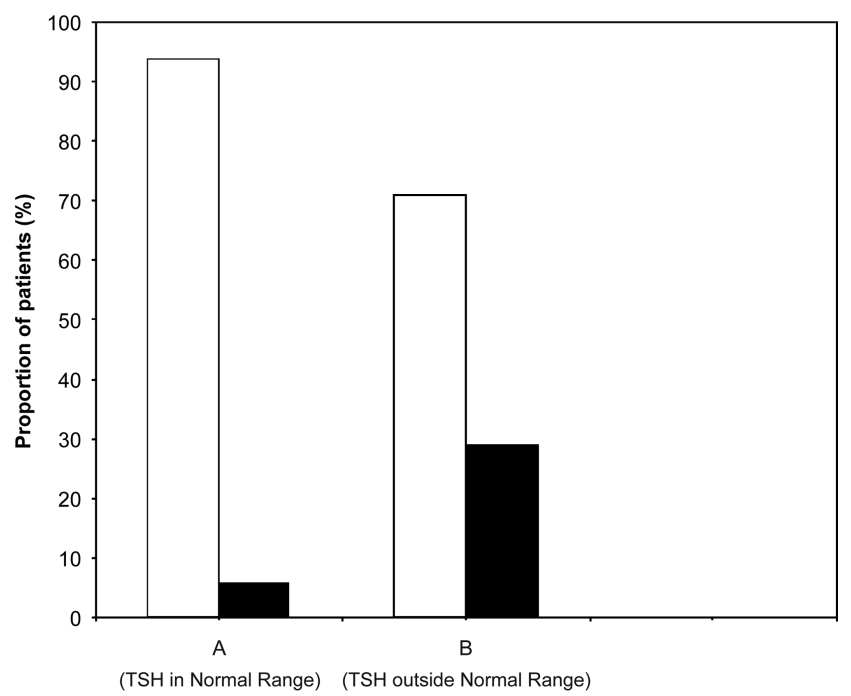

FIG. 2. Distribution of the outcomes of pregnancy in 63 women on L-thyroxine treatment as a function of their initial serum TSH (Group A=those with normal TSH, Group $\mathrm{B}=$ those with abnormal TSH). Open bars are data for pregnancies without fetal loss; solid bars are data for pregnancies with fetal loss. There was increased fetal loss $(p<0.05)$ in Group B (TSH values outside the reference range) compared to Group A (TSH within the reference range). 
Table 1. Serum Thyrotropin and Free Thyroxine

Values at First Control in Pregnant Women on Thyroxine Substitution Due to Hypothyroidism AND WITH FETAL Loss

\begin{tabular}{lclcccc}
\hline & & & & & First \\
Patient & Age & Diagnosis & $\begin{array}{c}\text { TSH } \\
(m I E / L)\end{array}$ & $\begin{array}{c}\text { FT } \\
(p M / L)\end{array}$ & $\begin{array}{c}\text { control } \\
\text { loseek })\end{array}$ & $\begin{array}{c}\text { loss } \\
\text { (week) }\end{array}$ \\
\hline 1 & 21 & St post GD & $<0.01$ & 26 & 8 & 10 \\
2 & 32 & St post GD & $<0.10$ & 20 & 6 & 7 \\
3 & 28 & AIT & 0.11 & - & 9 & 11 \\
4 & 36 & AIT & 0.21 & 20 & 9 & 24 \\
5 & 31 & AIT & 1.3 & 13 & 6 & 9 \\
6 & 32 & NoAIT & 3 & & 15 & 17 \\
7 & 28 & AIT & 5.8 & 13 & 11 & 14 \\
8 & 33 & AIT & 6 & & 5 & 8 \\
9 & 33 & NoAIT & 9.6 & 12 & 11 & 20 \\
10 & 21 & AIT & 15 & 15 & 3 & 7 \\
11 & 33 & NoAIT & 16 & 8 & 11 & 16 \\
\hline
\end{tabular}

areference range: $0.4-4.0 \mathrm{mIU} / \mathrm{L}$.

${ }^{\mathrm{b}}$ reference range: $9-22 \mathrm{pmol} / \mathrm{L}$.

AIT, autoimmune thyroiditis; St post GD, status post Graves' disease; NoAIT, hypothyroidism without AIT; $\mathrm{FT}_{4}$, free thyroxine.

TSH concentrations at their first antenatal visit. These findings are probably due to thyroid hormone requirements increasing very early in pregnancy, typically before the first obstetrical visit (15). In contrast, $20 \%$ of our patients on thyroxine substitution had a low TSH concentration at their first visit, also similar to the findings $(22.8 \%)$ of Vayida et al. (16). It has previously been suggested (15) and recently discussed by the Endocrine Society (3) that all women on thyroxine substitution should increase their thyroxine dose immediately on confirmation of pregnancy. However, our findings indicate that routinely increasing the thyroxine dose may result in oversubstitution in a substantial portion of these pregnant women. Moreover, 33\% of our patients did not have to increase the thyroxine dose during pregnancy.

During pregnancy thyroid physiology undergoes several well-established changes including an approximate doubling of thyroxine-binding globulin concentrations and an increase in plasma volume $(17,18)$, both contributing to an increase in the total thyroxine pool. In addition, there is the presence of Type III deiodinase activity in the placenta which degrades thyroid hormones. Finally gut thyroxine absorption may be decreased, with or without iron supplements that pregnant women often take. All of these factors are probably responsible for increased requirements for levothyroxine in hypothyroid pregnant women (19). Our observation that $67 \%$ of patients on thyroxine substitution at first visit had to increase the thyroxine dose during pregnancy was in accordance with previous studies $(14,15,19)$. The requirement for an increase in thyroxine dose was $50 \%$ (median), similar to previous studies $(14,20-21)$. In a majority of our patients the first blood sample was collected in the first trimester as was our goal. In these patients the first dose adjustment was made in week 11 (median, range week 3-32). This is in agreement with a previous study where the median onset of dose modification occurred at 8 weeks and some women required an increased dose in week 5 (15). A large body of evidence strongly suggests that thyroid hormone is an important factor contributing to normal fetal development (3). Early in pregnancy transfer of maternal thyroxine to the fetus is a requirement for the fetus; fetal production of thyroid hormones does not become efficient until mid-gestation (2). Therefore thyroid function in pregnant women on thyroxine substitution should be monitored early in pregnancy (i.e., as soon as pregnancy has been confirmed) to ensure adequate fetal supplies and should also be carefully followed during pregnancy.

Our finding of increased fetal loss in women having abnormal serum TSH when first tested is evidence that abnormal maternal thyroid status increases the risk of obstetrical complications. Interestingly we noted that four of the nine patients with fetal loss had a TSH value $<0.4 \mathrm{mIU} / \mathrm{L}$. In another study, however, subclinical hyperthyroidism was not associated with adverse outcome of pregnancy (11). Our findings of this association, however, need to be confirmed in a larger series of patients. Although several studies have reported that obstetrical and fetal complications occur with increased frequency in pregnant women with hypothyroidism $(2,9)$, there are few reports regarding the outcome of pregnancy in women with treated hypothyroidism. Abalovich et al. (6) demonstrated that adequate thyroxine treatment was very important for pregnancy outcome both in overt and subclinical hypothyroidism. With inadequate thyroxine treatment, pregnancy ended with abortion in $60 \%$ and $71 \%$ of women with overt and subclinical hypothyroidism, respectively, with an increased prevalence of preterm deliveries. Conversely, the frequency of abortions in hypothyroid pregnant women receiving adequate treatment was very low and in general they went to term without complications (6).

In summary, in $49 \%$ of pregnant women on thyroxine substitution for hypothyroidism, serum TSH values were abnormal when first tested and fetal loss was increased in this setting. Thyroid function in pregnant women on thyroxine substitution should be monitored early in pregnancy (i.e., as soon as pregnancy has been confirmed) and carefully followed during pregnancy. The thyroxine dose should be increased if TSH is elevated early in pregnancy as this is likely to decrease the risk of obstetrical complications. Further studies on the relationship between maternal subclinical thyrotoxicosis and adverse fetal outcome are needed.

\section{Acknowledgments}

This study was presented in part at the European Congress of Endocrinology Budapest April 28-May 2, 2007, and was supported by grants from the Research Funds Malmö University Hospital, Skåne Research Foundation and the Faculty of Medicine at Lund University and the Albert Påhlson foundation.

\section{Disclosure Statement}

No competing financial interests exist.

\section{References}

1. Glinoer D 1997 The regulation of thyroid function in pregnancy: pathways of endocrine adaptation from physiology to pathology. Endocr Rev 18:404-433.

2. Casey BM, Leveno KJ 2006 Thyroid disease in pregnancy. Obstet Gynecol 108:1283-1292.

3. Abalovich M, Amino N, Barbour LA, Cobin RH, De Groot LJ, Glinoer D, Mandel SJ, Stagnaro-Green A 2007 Clinical 
practice guideline. Management of thyroid dysfunction during pregnancy and postpartum: an Endocrine Society clinical practice guideline. J Clin Endocrinol Metab 92:S1S47.

4. Leung AS, Millar LK, Koonings PP, Montoro M, Mestman JH 1993 Perinatal outcome in hypothyroid pregnancies Obstet Gynecol 81:349-353.

5. Haddow JE, Palomaki GE Allan WC, Williams JR, Knight GJ, Gagnon J, O'Heir CE, Mitchell ML, Hermos RJ, Waisbren SE, Faix JD, Klein RZ 1999 Maternal thyroid deficiency during pregnancy and subsequent neuropsychological development of the child. N Engl J Med 341:549-555.

6. Abalovich M, Gutierrez S, Alcaraz G, Maccallini G, Garcia A, Levalle O 2002 Overt and subclinical hypothyroidism complicating pregnancy. Thyroid 12:63-68.

7. Casey BM, Dashe JS, Wells CE, McIntire DD, Byrd EW, Leveno KJ, Cunningham FG 2005 Subclinical hypothyroidism and pregnancy outcomes. Obstet Gynecol 105:239-245.

8. Negro R, Formoso G, Mangieri T, Pezzarossa A, Sazzi D, Hassan H 2006 Levothyroxine treatment in euthyroid pregnant women with autoimmune thyroid disease: effects on obstetrical complications. J Clin Endocrinol Metab 91: 2587-2591.

9. Brent GA 2007 Editorial. Diagnosing thyroid dysfunction in pregnant women: is case finding enough. J Clin Endocrinol Metab 92:39-41.

10. Anselmo J, Cao D, Karrison T, Weiss RE, Refetoff S 2004 Fetal loss associated with excess thyroid hormone exposure. JAMA 292:691-695.

11. Casey BM, Dashe JS, Wells CE, McIntire DD, Leveno KJ, Cunningham FG 2006 Subclinical hyperthyroidism and pregnancy outcomes. Obstet Gynecol 107:337-341.

12. Pekonen F, Teramo K, Ikonen E, Österlund K, Mäkinen T, Lamberg BA. 1984 Women on thyroid hormone therapy: pregnancy course, fetal outcome and amniotic fluid thyroid hormone level. Obstet Gynecol 63:635-638.
13. Kaplan MM. 1992 Monitoring thyroxine treatment during pregnancy. Thyroid 2:147-152.

14. Mandel SJ, Larsen PR, Seely EW, Brent GA 1990 Increased need for thyroxine during pregnancy in women with primary hypothyroidism. N Engl J Med 323:91-96.

15. Alexander EK, Marqusee EM, Lawrence J, Jarolim P, Fischer GA, Larsen PR 2004 Timing and magnitude of increases in levothyroxine requirements during pregnancy in women with hypothyroidism $2004 \mathrm{~N}$ Engl J Med 351:241-249.

16. Vaidya B, Anthony S, Bilous M, Shields B, Drury J, Hutchison S, Bilous R 2007 Detection of thyroid dysfunction in early pregnancy: universal screening or targeted high-risk case finding? J Clin Endocrinol Metab 92:203-207.

17. Burrow GN, Fisher DA, Larsen PR 1994 Maternal and thyroid function N Engl J Med 331:1072-1078.

18. Glinoer D, de Nayer $P$, Bourdoux $P$, Lemone M, Robyn C, van Steirteghem A, Kinthaert J, Lejeune B 1990 Regulation of maternal thyroid during pregnancy. J Clin Endocrinol Metab 71:276-287.

19. Brent G 1999 Maternal hypothyroidism: recognition and management. Thyroid 9:661-665.

20. Roti E, Minelli R, Salvi M 1996 Management of hyperthyroidism and hypothyroidism in the pregnant woman. J Clin Endocrinol Metab 81:1679-1682.

21. Smallridge RC, Ladenson PW 2001 Hypothyroidism in pregnancy: consequences to neonatal health. J Clin Endocrinol Metab 86:2349-2353.

Address reprint requests to: Bengt Hallengren, M.D., Ph.D.

Department of Endocrinology

Malmö University Hospital

SE-205 02 Malmö

Sweden

E-mail: bengt.hallengren@med.lu.se 